Textures and Microstructures, 1988, Vols. 8 \& 9, pp. 247-263

Reprints available directly from the publisher

Photocopying permitted by license only

(C) 1988 Gordon and Breach Science Publishers Inc.

Printed in the United Kingdom

\title{
An X-ray Study on Texture Caused by Rolling Contact
}

\section{SHIN-ICHI NAGASHIMA}

\author{
Formerly: Department of Mechanical Engineering, Yokohama National \\ University, Yokohama, \\ now:Central $R$ \& D Bureau, 1st $R$ \& D Laboratories, Nippon Steel Corporation, \\ Kawasaki, Japan
}

TOSHINORI OHTSUBO

Formerly: Department of Mechanical Engineering, Yokohama National

University, Yokohama,

now: Yawata Works, Nippon Steel Corporation, Kitakyushu, Japan

(Received 6 July 1987; in final form 27 December 1987)

Dedicated to the memory of Professor Günter Wassermann

Rolling contact loading causes a remarkable plastic flow at the contact surface of rail and wheel or the surface of a pair of disks rotating under normal force. It is supposed that significant residual stress, work hardening and preferred orientation will be introduced as well as the plastic flow, and the combination of all of those factors may cause the fatigue damage to the specimen. In the present study, the mode of plastic flow and the preferred orientation with respect to the tangential force, or slip at the contact region were measured. The experimental results were nearly the same for both laboratory tested disk specimen and a used rail. The distribution of degree of plastic flow showed good agreement with the work hardening of the flowed region, besides the mode of plastic flow is nearly the same as the calculated result. The major texture component at the flowed region was near (111) [110] and near (111) $[11 \overline{2}]$ which are the major components of cold rolling texture being formed by the combination of compressive stress and weak shear stress.

KEY WORDS: Rolling contact, surface texture, work hardening.

\section{INTRODUCTION}

In order to clarify the rolling contact fatigue phenomenon of rails, numbers of studies have been carried out on plastic flow, and 
change in mechanical properties of steels under rolling-sliding contact. Rolling contact fatigue can be simulated by a laboratory test using a pair of disks rotating under loads exceeding the yield point. It was pointed out by Crook (1979) and Welsh (1957) that remarkable plastic flow is observed at the surface layer of disks, and the direction of the plastic flow is opposite to the rolling direction. Johnson and his co-workers have explained why the forward plastic flow occurs under pure rolling contact (Johnson and Jefferis, 1963, Merwin and Johnson, 1963, Johnson, 1963).

The present authors have studied residual stress in the plastically flowed region caused by rolling contact of disk specimens and a used rail under pure rolling contact, friction rolling contact and rolling-sliding contact (Nagashima et al., 1983, Nagahsima et al., 1984, Nagashima et al., to be published). In the present study, the texture of the plastic layers was examined with the same specimen as the former study.

\section{EXPERIMENTS}

\section{Specimens}

Two kinds of specimen i.e. laboratory fatigue test specimens (Steel A) and a used rail (Steel B) were measured. The chemical composition and mechanical properties of the steels are shown in Table 1.

\section{Testing condition}

(a) Rolling contact

In the present study, three kinds of rolling contact condition were obtained with or without forced gear drive, and by a combination of gear ratio and different diameter size of disks as shown in Table 2.

Table 1 Chemical composition and mechanical properties of steels ( $*$ :MPa)

\begin{tabular}{lllllllllll}
\hline Steel & $\begin{array}{l}\mathrm{C} \\
(\mathrm{wt} \%)\end{array}$ & $\begin{array}{l}\mathrm{Si} \\
(\mathrm{wt} \%)\end{array}$ & $\begin{array}{l}\mathrm{Mn} \\
(\mathrm{wt} \%)\end{array}$ & $\begin{array}{l}\mathrm{P} \\
(\mathrm{wt} \%)\end{array}$ & $\begin{array}{l}\mathrm{S} \\
(\mathrm{wt} \%)\end{array}$ & $\begin{array}{l}\mathrm{Cu} \\
(\mathrm{wt} \%)\end{array}$ & $\begin{array}{l}\text { PS } \\
(*)\end{array}$ & $\begin{array}{l}\mathrm{TS} \\
(*)\end{array}$ & $\begin{array}{l}\mathrm{El} \\
(\%)\end{array}$ & $\begin{array}{l}\text { RA } \\
(\%)\end{array}$ \\
\hline $\mathrm{A}$ & 0.36 & 0.26 & 0.72 & 0.024 & 0.028 & 0.27 & 327 & 651 & 38.0 & 65.0 \\
$\mathrm{~B}$ & 0.67 & 0.21 & 0.85 & 0.015 & 0.018 & - & 490 & 911 & 13.5 & 21.5 \\
\hline
\end{tabular}


Table 2 Testing condition and combination of gear ratio and disk diameter

\begin{tabular}{|c|c|c|c|c|}
\hline $\begin{array}{l}\text { Rolling } \\
\text { condition }\end{array}$ & $\begin{array}{l}\text { Forced gear } \\
\text { drive }\end{array}$ & $\begin{array}{l}\text { Gear } \\
\text { ratio }\end{array}$ & $\begin{array}{l}\text { Disk diameter } \\
\mathrm{mm}\end{array}$ & Slip rate \\
\hline Pure rollin & Used & $60 / 66$ & $31.4 / 28.6$ & 0 \\
\hline Friction drive & None & None & $31.4 / 28.6$ & 0 \\
\hline Rolling sliding & Used & $56 / 70$ & $31.4 / 28.6$ & $12.1-13.7 \%$ \\
\hline
\end{tabular}
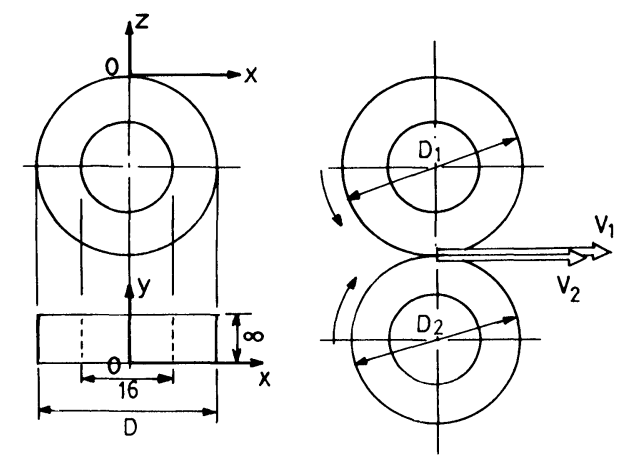

Figure 1 The size and alignment of disk specimen.

The alignment of disks is shown in Figure 1, the slip rate is given by the following equation;

$$
\begin{aligned}
& s_{1}=\left(v_{1}-v_{2}\right) / v_{1} \\
& s_{2}=\left(v_{2}-v_{1}\right) / v_{2}
\end{aligned}
$$

where, $v_{1}$ and $v_{2}$ are the velocity at the top surface of disks. The testing conditions are shown in Table 3.

\section{(b) The history of the used rail}

The specimen was prepared from a rail used at the Shinkansen Line of the Japanese National Railway. The number of passage of wheels are estimated to be about 40 million. As the diameter of a new wheel is $910 \mathrm{~mm}$, and the load on a wheel is about $78.5 \mathrm{kN}$, the maximum Hertz' stress is estimated to be $790 \mathrm{MPa}$. 
Table 3. The specimen numbers and the condition of rolling contact

\begin{tabular}{|c|c|c|c|c|c|c|c|}
\hline \multicolumn{2}{|c|}{$\begin{array}{l}\text { Specimen } \\
\text { Number }\end{array}$} & $\begin{array}{l}\text { Diameter } \\
\text { of disks } \\
\text { D } \\
\text { mm }\end{array}$ & $\begin{array}{l}\text { Slip rate } \\
\text { initial/final } \\
\% / \%\end{array}$ & $\begin{array}{l}\text { Revolution } \\
\times 10^{4}\end{array}$ & $\begin{array}{l}\text { Theoretical } \\
\text { contact } \\
\text { breadth } \\
\mathrm{a}, \mathrm{mm}\end{array}$ & $\begin{array}{l}\text { Load } \\
\mathrm{P}, \mathrm{kN}\end{array}$ & $\begin{array}{l}\text { Max. } \\
\text { contact } \\
\text { stress } \\
\text { GPa }\end{array}$ \\
\hline \multirow[t]{2}{*}{ P1 } & P1-1 & 31.42 & $-0.01 / 0.03$ & 0.9 & 0.18 & 2.35 & 1.34 \\
\hline & P1-2 & 28.57 & $0.01 / 0.03$ & 1.0 & & & \\
\hline \multirow[t]{2}{*}{ P2 } & P2-1 & 31.43 & $-0.08 / 0.02^{\mathrm{a}}$ & 36.0 & 0.19 & 2.94 & 1.20 \\
\hline & P2-2 & 28.60 & $0.08 / 0.02^{b}$ & 40.0 & & & \\
\hline \multirow[t]{2}{*}{ P3 } & P3-1 & 31.43 & $-0.01 / 0.04$ & 90 & 0.17 & 2.94 & 1.31 \\
\hline & P3-2 & 28.58 & $0.01 / 0.04$ & 100 & & & \\
\hline \multirow[t]{2}{*}{ RS } & RS-1 & 31.43 & $-13.7 / 13.6$ & 0.27 & 0.15 & 2.35 & 1.14 \\
\hline & RS-2 & 28.60 & $12.1 / 11.9$ & 0.30 & & & \\
\hline \multirow[t]{2}{*}{ FR } & FR-1 & 31.42 & - - & 36.0 & 0.18 & 2.94 & 1.34 \\
\hline & FR-2 & 28.41 & --- & 40.0 & & & \\
\hline
\end{tabular}

a $-13.7 \%$ slip rate was applied for the first 300 revolution, then the test was continued under $-0.08 \%$ slip rate.

b $12.1 \%$ slip rate was applied for the first 300 revolution, then the test was continued under $0.8 \%$ slip rate.

\section{Experimental condition for the $\mathrm{X}$-ray pole figure measurement}

(110) pole figure was measured by the use of Co $K \alpha$ radiation and Schulz' reflection method.

(a) Measurement of X-ray diffraction width

The width of X-ray diffraction line was measured at the surface and the inner layers by removing the layers by electrolytic polishing. The profile of 211 diffraction lines were measured by the use of $\mathrm{Cr} K \alpha$ radiation.

(b) Observation of plastic flow region

The plastic flow near the surface layer was observed by an optical microscope with the polished and etched surfaces, which are perpendicular to the longitudinal and the transverse directions.

(c) Measurement of micro Vickers hardness

Micro Vickers hardness was measured applying the load of $1.96 \mathrm{~N}$, along the radial direction from the top surface to the deeper region. The values of 5 points at equal depth were averaged. 
Table 4. Plastic flow of the test specimen

\begin{tabular}{|c|c|c|c|c|c|c|c|}
\hline \multicolumn{2}{|c|}{$\begin{array}{l}\text { Specimen } \\
\text { number }\end{array}$} & \multirow{2}{*}{$\begin{array}{l}\begin{array}{l}\text { Slip rate } \\
\text { initial/final } \\
(\%)\end{array} \\
-0.007 / 0.027\end{array}$} & \multirow{2}{*}{$\begin{array}{l}\text { Revolution } \\
10^{4} \\
0.9\end{array}$} & \multirow{2}{*}{$\begin{array}{l}\begin{array}{l}\text { Load } \\
\mathrm{kN}\end{array} \\
2.35\end{array}$} & \multirow{2}{*}{$\begin{array}{l}\text { Mode } \\
\text { pure }\end{array}$} & \multirow{2}{*}{$\begin{array}{l}\begin{array}{l}\text { Region of } \\
\text { forward } \\
\text { flow, } \mu \mathrm{m}\end{array} \\
55 / 220\end{array}$} & \multirow{2}{*}{$\begin{array}{l}\text { Backward } \\
\text { flow } \\
\text { none }\end{array}$} \\
\hline P1 & P1-1 & & & & & & \\
\hline & P1-2 & $0.007 / 0.027$ & 1.0 & & rolling & $70 / 250$ & obs. \\
\hline \multirow[t]{2}{*}{ P2 } & P2-1 & $-0.079 / 0.022$ & 36.0 & 2.94 & a & $70 / 270$ & none \\
\hline & P2-2 & $0.079 / 0.022$ & 40.0 & & & $85 / 305$ & none \\
\hline \multirow[t]{2}{*}{ P3 } & P3-1 & $-0.012 / 0.040$ & 90 & 2.94 & pure & $55 / 350$ & none \\
\hline & P3-2 & $0.012 / 0.040$ & 100 & & rolling & $75 / 310$ & obs. \\
\hline \multirow[t]{2}{*}{ RS } & RS-1 & $-13.7 / 13.6$ & 0.27 & 2.35 & forced & $0 / 420$ & none \\
\hline & RS-2 & $12.1 / 11.9$ & 0.30 & & rolling & none & $0 / 400$ \\
\hline \multirow[t]{2}{*}{ FR } & FR-1 & $<0$ & 36.0 & 2.94 & friction & $70 / 290$ & none \\
\hline & FR-2 & $>0$ & 40.0 & & rolling & $90 / 320$ & obs. \\
\hline
\end{tabular}

${ }^{\mathrm{a}}$ To the specimen $\mathrm{P} 2$, sliding-rolling contact of slip rate as large as $\pm 12 \%$ was applied for about 300 revolution and then smaller slip rolling contact test as shown in Table 3 was carried out.

\section{EXPERIMENTAL RESULTS AND DISCUSSION}

\section{Plastic flow of disk specimen}

The mode of plastic flow was observed with the cross section at the central plane of the thickness direction of the disks, and the results are shown in Table 4.

The typical mode of plastic flow caused by rolling contact is shown in Figure 2, and the results are summarized as follows:

(1) In the case of rolling contact with a small negative slip less than $0.04 \%$, no plastic flow was observed at the surface layer and forward flow was observed at deeper layers than 55-90 $\mu \mathrm{m}$ from the

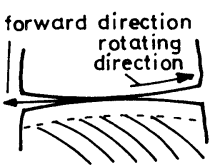

(a) $s=0$

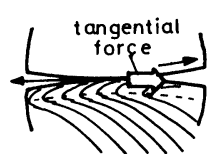

(b) $s>0$

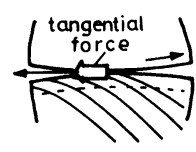

(c) $s<0$

Figure 2 Plastic flow pattern caused by rolling contact. (a) Pure rolling contact, (b) Rolling-sliding contact with positive tangential force, (c) Rolling-sliding contact with negative tangential force. 
surface. In the case of such a small positive slip as $0.04 \%$, slight backward flow was observed at the layer just below the surface.

2) In the case of friction driven rolling contact without gear drive, nearly the same mode of plastic flow as described above was observed.

3) In the case of rolling-sliding contact with the slip rate of more than $12 \%$, a significant plastic flow was observed from the top surface to the deeper region. Positive slip rate gives a significant backward flow, while negative slip gives a forward flow in the same region. The reason why the plastic flow turns to the opposite direction from the forward flow is explained to be due to the large tangential force applied at the contact region of the pair of disks.

\section{$X$-ray line broadening and hardness change along depth direction of disk specimen}

An evident X-ray diffraction line broadening and work hardening were observed at the plastically flowed region. And there are apparent differences between slightly and severely deformed region.

(a) The case of pure rolling contact

The change in hardness and in diffraction line broadening are illustrated in Figure 3(a). Figure 3(a) shows the case of nearly pure rolling contact; i.e., small slip ratio less than $0.04 \%$. The larger load and longer testing time cause larger broadening and hardness which decrease gradually along the inner region from the surface. The specimen P2 was tested with a severe slip rate as $13.7 \%$ for 300 cycles in the beginning. Testing then continued at a small slip rate of $0.02 \%$ for about 400 thousand times under the same load. It is clear that severe slip in the early stage of test affects work hardening to deeper region about $0.6 z / a$ (about $0.01 \mu \mathrm{m})$ from the surface.

The effect of friction rolling contact on the diffraction line broadening and work hardening was nearly the same as in nearly pure rolling contact.

(b) The case of rolling-sliding contact

The result of rolling-sliding contact was shown in Figure 3(b), where RS-1 and RS-2 show the result of the case $s=-13.6 \%$ and $s=11.9 \%$, respectively. Both show siginficant hardening and line broadening at the surface layer, decreasing in the inner region. 


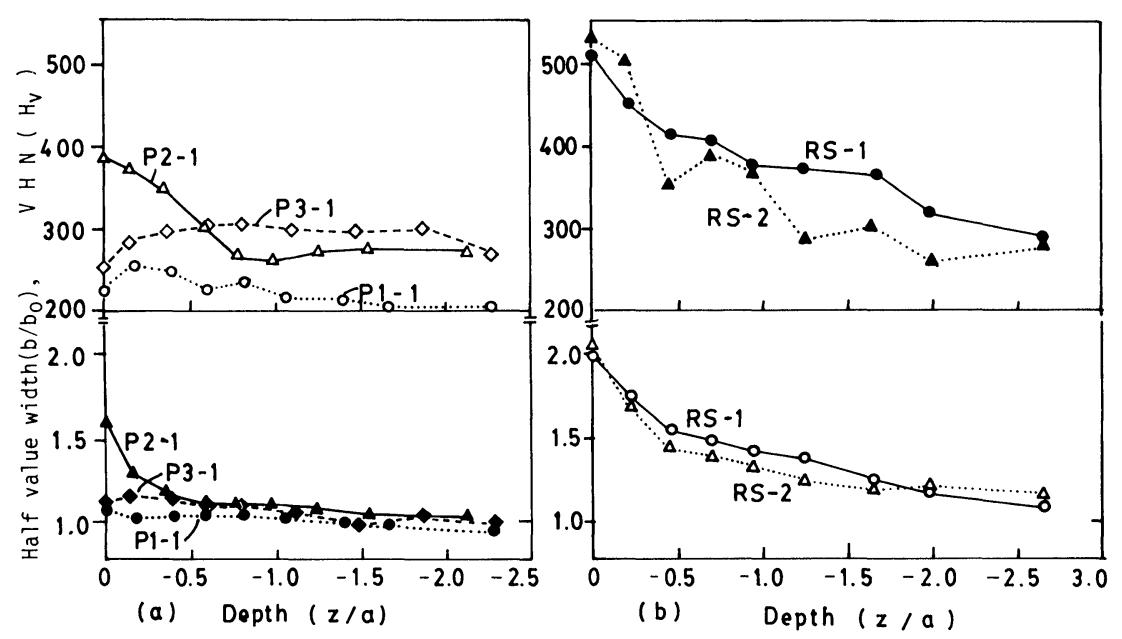

Figure 3 Change in micro-Vickers hardness and half value width of 211 diffraction line (a) Pure rolling contact, (b) Rolling-sliding contact, slip rate is larger than $12 \%$.

\section{Plastic flow and work hardening of the used rail}

It is reported by Sugino and Kageyama (1979) that a positive plastic flow occurs at the surface of used rail in the field side and negative one in the gauge corner side. This is considered to be due to the shape of wheel tread; i.e., the tread is conical and the diameter of tread at the gauge corner side is larger than that of the field side. In the present study, the same tendency in the plastic flow was found on the cross section of the specimen that is cut parallel to the $x-z$ plane at the points $y=-18.5,-8.5,-3.5,1.5,6.5,16.5$ and 26.5 $\mathrm{mm}$, where the Cartesian co-ordinate $x, y$ and $z$ to the rail is shown in Figure 4.

The degree of plastic flow was represented by $F_{x}=\cot \theta_{x}$, and $F_{y}=\cot \theta_{y}$, where the angle between the surface plane (along $x$ or $y$ direction) and the flow line is $\theta_{x}$ or $\theta_{y}$, respectively. The degree of plastic flow, such as magnitude, direction and thickness of flowed zone, as well as hardening caused by plastic flow are shown in Figure 5. It is clear that positive and negative flows are observed at the field side and the gauge corner side, respectively, the same as 

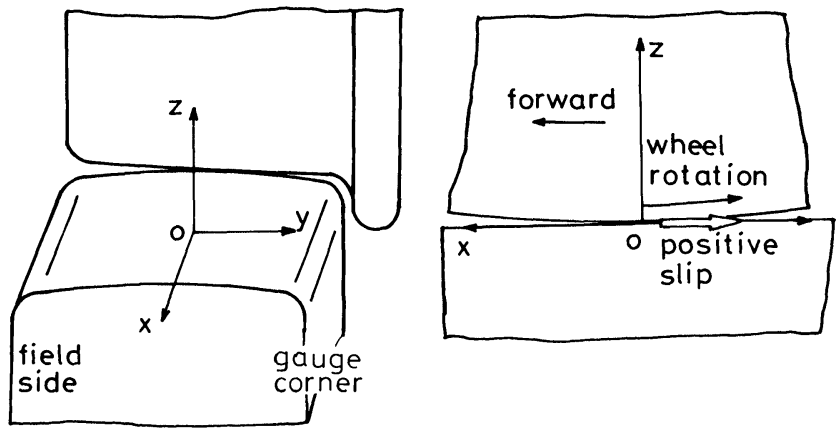

Figure 4 Coordinate system of rail and the direction of wheel rotation.

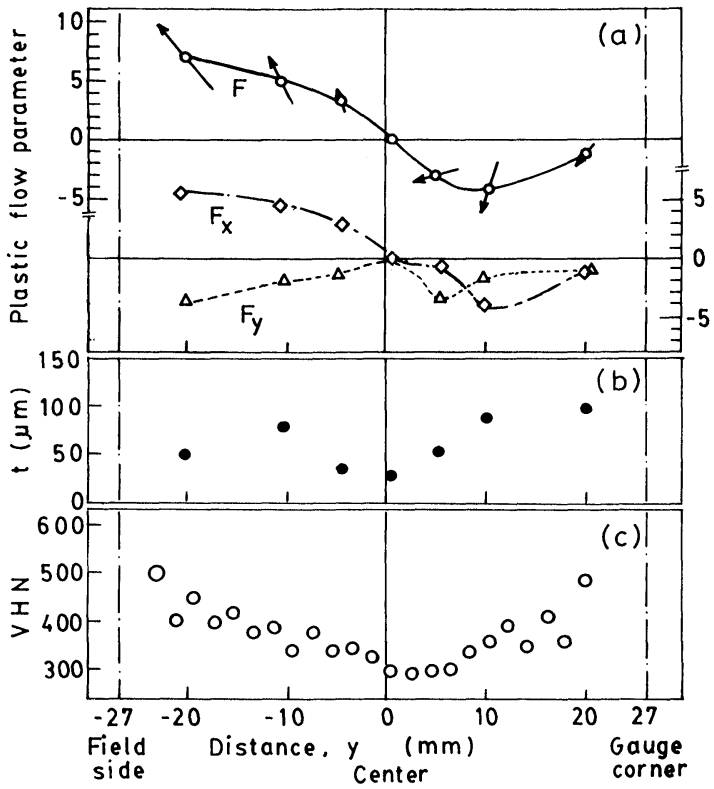

Figure 5 Variation of plastic flow, $F, F_{x}, F_{y}$, thickness of flowed region, $t$, and micro Vickers hardness number, VHN, in the transverse direction. 
found in the previous study. Furthermore, thickness of flowed layer and the hardness are large at both sides but are rather small at the central region where no or little plastic flow was observed.

\section{Discussion on plastic flow}

Merwin and Johnson (1963) has calculated the plastic flow as well as the residual stress distribution caused by repeated cyclic rollingsliding contact under the following assumptions:

1) This was solved as a contact problem of a rigid cylinder on the plane surface of semi-infinite solid.

2) The material of both bodies is elastic-perfectly plastic and isotropic.

3) The specimen deforms under plane strain criterion.

4) The stress distribution near the contact region is defined by the Hertz equation.

If the loading cycle is entirely elastic, the residual stresses and residual strains would approach zero from the above-described assumptions:

and

$$
\begin{aligned}
& \left(\sigma_{x}\right)_{r}=f_{1}(z), \quad\left(\sigma_{y}\right)_{r}=f_{2}(z) \\
& \left(\sigma_{z}\right)_{r}=\left(\tau_{x y}\right)_{r}=\left(\tau_{y z}\right)_{r}=\left(\tau_{z x}\right)_{r}=0
\end{aligned}
$$

$$
\begin{aligned}
& \left(\varepsilon_{z}\right)_{r}=f_{3}(z), \quad\left(\gamma_{z x}\right)_{r}=f_{4}(z) \\
& \left(\varepsilon_{x}\right)_{r}=\left(\gamma_{x y}\right)_{r}=\left(\gamma_{y z}\right)_{r}=\left(\gamma_{z x}\right)_{r}=0
\end{aligned}
$$

As the result of plastic deformation, however, residual stresses $\left(\sigma_{z}\right)_{r}^{\prime}$ and $\left(\tau_{z x}\right)_{r}^{\prime}$ have non-zero values, and the residual strains $\left(\varepsilon_{z}\right)_{r}$ and $\left(\gamma_{z x}\right)_{r}$ are given by

$$
\left(\varepsilon_{z}\right)_{r}=-\frac{(1-2 v)}{2(1-v) G}\left(\sigma_{z}\right)_{r}^{\prime}
$$

and

$$
\left(\gamma_{z x}\right)_{r}=-\frac{\left(\tau_{z x}\right)_{r}^{\prime}}{G}
$$

Furthermore, the tangential displacement of the surface pass, being 
denoted by $\delta$, may be given by the increment residual strain $\left(\gamma_{z x}\right)_{r}$

$$
\delta=\int_{z_{1}}^{z_{2}}\left(\gamma_{z x}\right)_{r} d z
$$

In the present study, Johnson's model was modified by taking the work hardening into consideration. In the case of steel the relation between stress $\sigma$ and strain $\varepsilon$ is given by

$$
\sigma=F \varepsilon^{n}
$$

where $F$ is constant and $n$ is the work-hardening exponent. In the case of rolling contact, $\varepsilon$ is a function of the number of repeated loading, $N$ and is represented by

$$
\begin{aligned}
\varepsilon & =\varepsilon_{e} g(N) \\
g(N) & =1-1 /(N+1)^{a}
\end{aligned}
$$

where, $\varepsilon_{e}$ is the total sum of residual strain $\left(\varepsilon_{z}\right)_{r}$, and $a$ is a constant. In this study, $a$ is given by the assumption that work hardening was saturated after repeating the loading as many as 20 times. The values of $a$ and $g(N)$ and $g(N)^{n}$ after $N$ cycle of repeated loading are shown in Table 5.

If it is assumed that $\sigma=\sigma_{B}$ when $\varepsilon=\varepsilon_{e}$, then

$$
F=\sigma_{B} / \varepsilon_{e}^{n}
$$

Then, the yield point of simple shear, $k$, or work hardened specimen will be given by

$$
k=\left(\frac{\sigma_{B}}{\sqrt{3}}\right) \cdot g(N)^{n}
$$

In the calculation, the shakedown limit after the work hardening is saturated was assumed to have $p_{0} / k=4.0$, and $n=0.25$. The result of calculation, i.e., the degree of plastic flow, $\delta / a$, along

Table 5. Values of $g(N)$ and $g(N)^{n}$ when $a=1.33$ and $n=0.25$

\begin{tabular}{llllllllllll}
\hline cycle, $N$ & 1 & 2 & 4 & 6 & 8 & 10 & 12 & 14 & 16 & 18 & 20 \\
\hline$g(N)$ & 0.602 & 0.768 & 0.882 & 0.925 & 0.946 & 0.959 & 0.967 & 0.973 & 0.977 & 0.980 & 0.983 \\
$g(N)^{n}$ & 0.881 & 0.936 & 0.969 & 0.981 & 0.986 & 0.990 & 0.992 & 0.994 & 0.994 & 0.995 & 0.996 \\
\hline
\end{tabular}




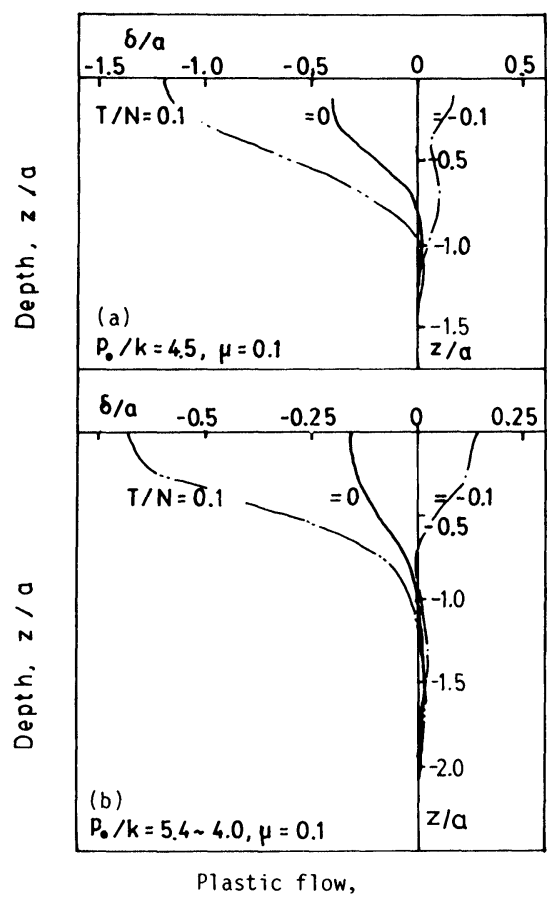

Figure 6 Plastic flow along londitudinal direction, $o / a$, caused by rolling contact. Calculated for 3 levels of tangential force: $T / N=0.1,0,-0.1$. $a$ : semi-contact width.

depth direction is shown in Figure 6; (a) shows the difference of plastic flow when the ratio of tangential force to normal force, $T / N=0.1, \quad 0,-0.1$, normalized load $p_{0} / k=4.5$ and friction coefficient $\mu=0.1$, and (b) shows the plastic flow for the ratio $T / N=0.1,0,-1.0$ in a work hardening model. This calculation gave the same result as the schematic illustration of the direction of plastic flow and tangential force, and the calculated depth of flowed region is nearly the same as the experiment (Table 4).

\section{Texture of the plastically flowed layer of disk specimen}

$\mathrm{X}$-ray pole figures were measured and shown in Figures 7-9. Specimens tested under nearly pure rolling contact and friction 


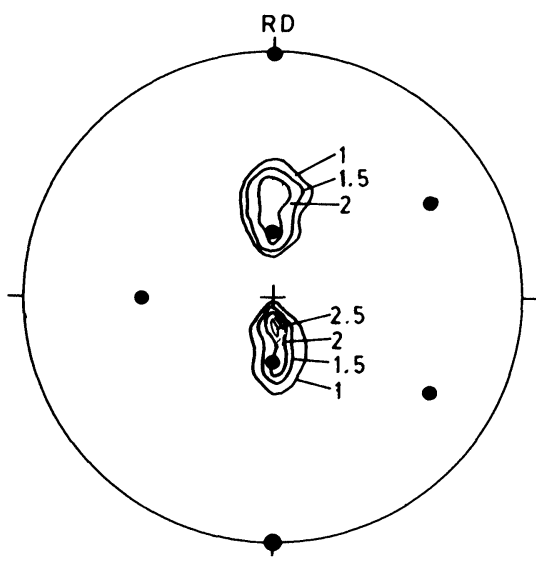

(a) $\mathrm{P} 1-1, z=-100 \mu \mathrm{m}$ - (112)[11̄0]

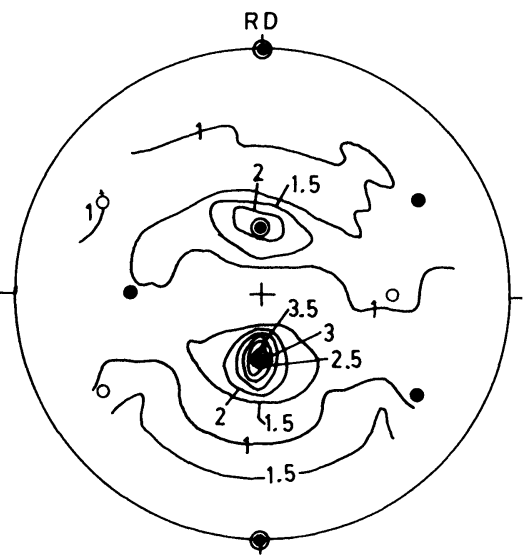

(b) $P 1-1, z=-251 \mu \mathrm{m}$

- (112)[11̄0]

$\circ(112)[\overline{1} 10]$

Figure 7 (110) Pole figure of disk specimen under rolling contact fatigue test. Load $=2.35 \mathrm{~N}$, revolutions $=1 \times 10^{4}$, slip rate $=-0.027 \%$.

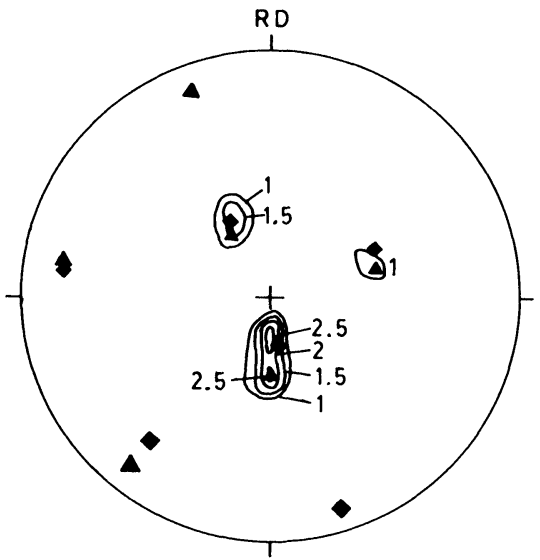

(a) $P 2-1, z=-109 \mu \mathrm{m}$ $\triangle(111)[\overline{1} \overline{1} 2] 10^{\circ} \mathrm{RD}+10^{\circ} \mathrm{ND}$ -(332)[iī3] $10^{\circ} \mathrm{RD}+10^{\circ} \mathrm{ND}$

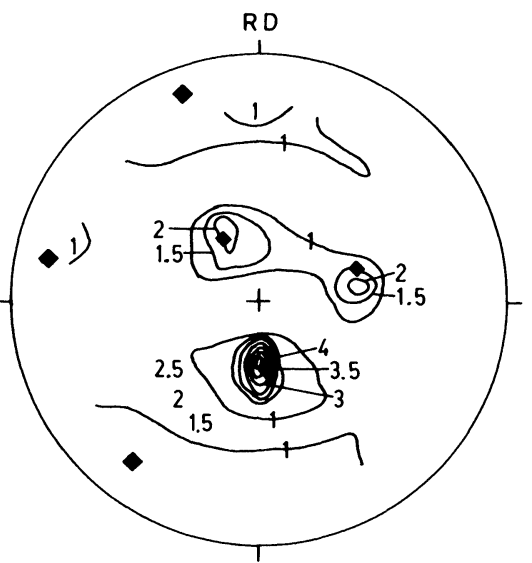

(b) $P 2-1, z=-301 \mu \mathrm{m}$

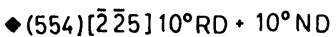

Figure 8 (110) Pole figure of disk specimen under rolling contact fatigue test. Load $=3.6 \mathrm{~N}$, revolutions $=3.6 \times 10^{5}$, slip rate $=-0.022 \%$. 


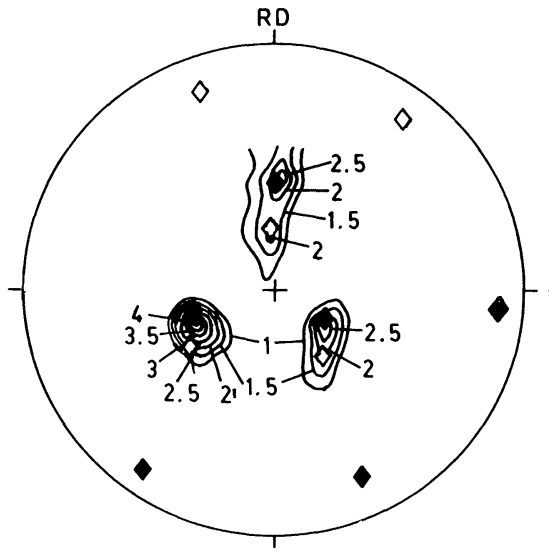

(a)FR-1, $z=-25 \mu \mathrm{m}$

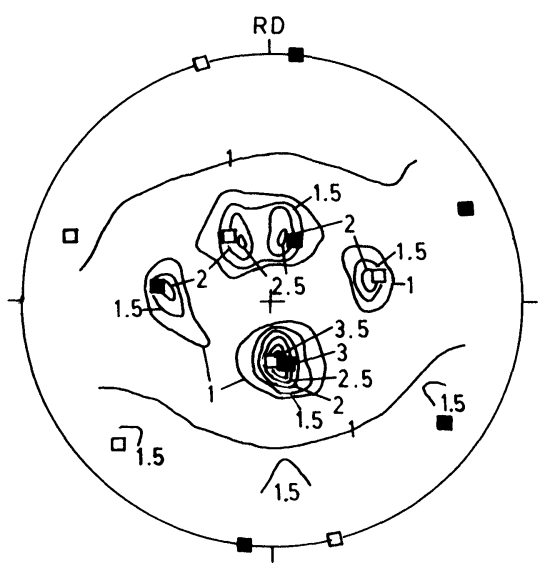

(c) FR-1, $z=-106 \mu \mathrm{m}$

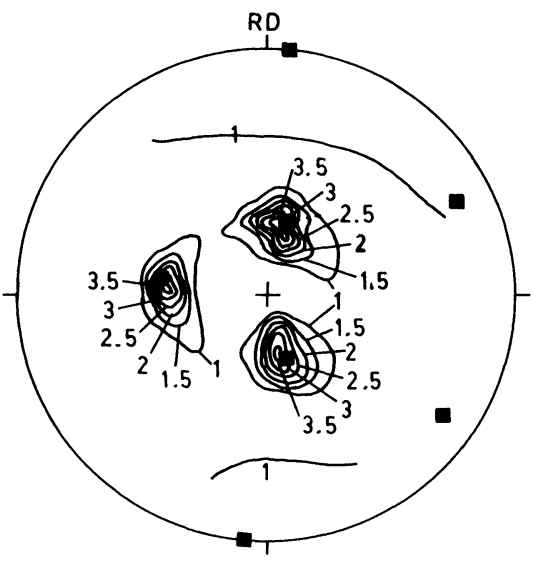

(b) $F R-1, z=-79 \mu \mathrm{m}$

( $(223)[\overline{3} \overline{3} 4] 5^{\circ}$ ND

$\diamond(332)[\overline{1} \overline{1} 3] 5^{\circ} \mathrm{RD}+5^{\circ} \mathrm{ND}$

- (223)[1110] $5^{\circ} \mathrm{ND}$

口 (223) [1 10$]-14^{\circ} \mathrm{ND}$

Figure 9 (110) Pole figure of disk specimen under rolling contact fatigue test. Load $=2.94 \mathrm{~N}$, revolutions $=3.6 \times 10^{5}$, slip rate $=$ nil $($ friction drive) .

driven rolling contact showed only slightly different textures, whereas such a severe slip rate as rolling-sliding contact in RS gave no evidence of preferred orientation. It is difficult to identify the precise orientation components from one incomplete pole figure, but the major component was roughly estimated from the position of pole density peaks. The results are as follows: $(\sim$ means the 


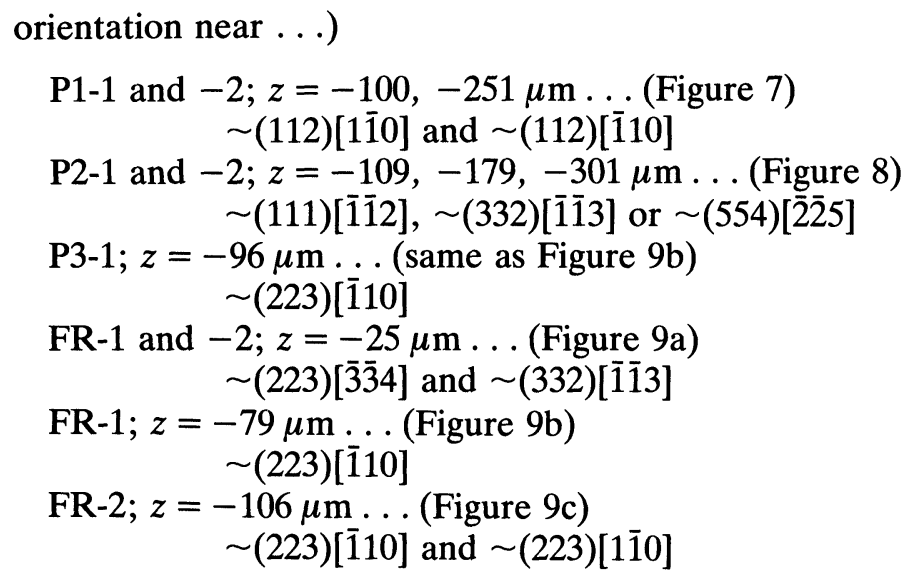

\section{Texture of the surface region of the used rail}

The pole figure of the surface layer of the rail was measured.

Sharp preferred orientation was observed at the central region, but no texture was observed at both gauge corner and field sides where severe flow has occurred, similar to the case of rolling contact fatigue specimen.

Some examples of (110) pole figures at the central region are shown in Figure 10. The major texture components are: near (554)[225] at the top surface (Figure 10a), and near (554)[225] or near (445)[110] at about $5 \mu \mathrm{m}$ inner layer from the surface (Figure $10 \mathrm{~b}$ ), and these are very similar to Figure 9a. But the surface layers at $y=-7 \mathrm{~mm}$ and $y=7 \mathrm{~mm}$ were nearly random.

\section{Discussion on the texture formation}

(a) Calculation of texture due to contact rolling

Textures due to contact rolling were calculated in the same way as reported by Dillamore and Katoh $(1971,1974)$. The coordinate system for the specimen $R$ and the crystal $A$ were defined by

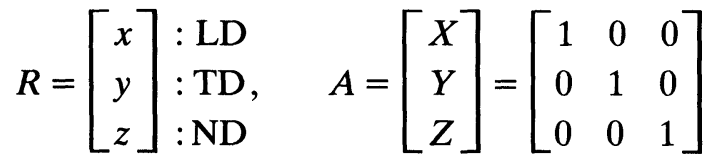




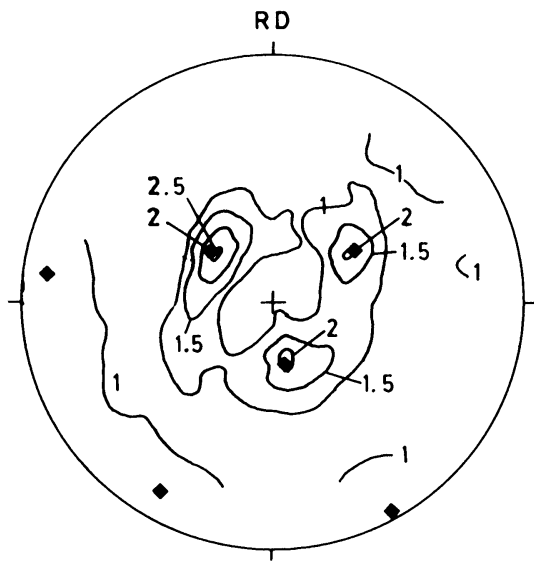

(a) Center $(y=0), z=0 \mu \mathrm{m}$

- (554)[225] $5^{\circ} \mathrm{RD}+-5^{\circ} \mathrm{ND}$

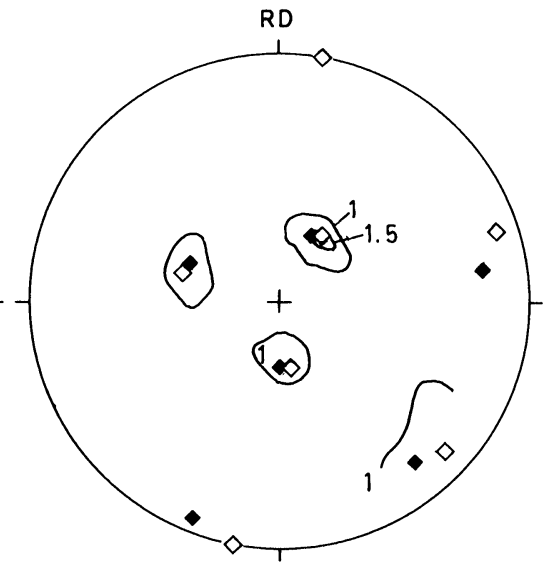

(b) Center $(y=0), \quad z=-5 \mu \mathrm{m}$ - (554) $[22 \overline{5}]-5^{\circ} \mathrm{RD} \cdot-10^{\circ} \mathrm{ND}$ $\diamond(445)[1 \overline{1} 0] 10^{\circ} R D$

Figure 10 (110) Pole figure of used rail, central region.

The rotation of crystallites under smaller strain were calculated on the following models (axes $x, y, z$ are denoted by $1,2,3$, respectively):

(1) Rolling strain model

$d \varepsilon_{33}=-d \varepsilon_{11}=-d \varepsilon_{r} \quad\left(d \varepsilon_{r}>0\right)$

other $d \varepsilon_{i j}=0$

strain increment for one path $\Delta \varepsilon=0.0367$

(2) Pure shear model

$d \varepsilon_{31}=d \varepsilon_{13}=d \varepsilon_{s} \quad\left(d \varepsilon_{s}>0\right)$

other $d \varepsilon_{i j}=0$

strain increment for one cycle $\Delta \varepsilon=0.06$

(3) Axial strain model

$d \varepsilon_{33}=-d \varepsilon_{22}=-d \varepsilon_{a} \quad\left(d \varepsilon_{a}>0\right)$

other $d \varepsilon_{i j}=0$

strain increment for one cycle $\Delta \varepsilon=0.0367$

(4) Combination of models (1) and (2)

(5) Combination of models (3) and (2)

The result of calculation on the preferred orientation components 
by the above models are as follows:

(1) Model 1

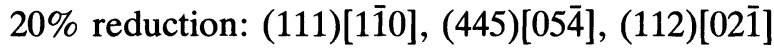

(2) Model 2 shear strain $=0.3:(223)[18 \overline{6}],(114)[3 \overline{7} 1],(012)[3 \overline{2} 1]$

(3) Model 3

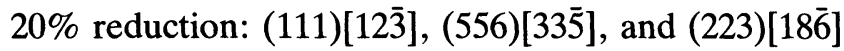

(4) Combination of Model 1 and Model 2 (20\% reduction)
(a) $d \varepsilon_{31}=0.01:$
$(112)[02 \overline{1}]$
(b) $d \varepsilon_{31}=0.05$ :

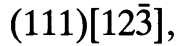
(334) $[04 \overline{3}], \quad(223)[18 \overline{6}], \quad$ and
$(111)[16 \overline{7}], \quad(233)[3 \overline{3} 1], \quad(122)[2 \overline{1} 0], \quad$ and (122)[457]

(5) Combination of Model 3 and Model 2 (20\% reduction)

(a) $d \varepsilon_{31}=0.01:(111)[12 \overline{3}],(223)[18 \overline{6}],(447)[34 \overline{4}]$

(b) $d \varepsilon_{31}=0.05:(335)[23 \overline{3}],(112)[6 \overline{8} 1],(347)[81 \overline{4}]$,

(b) Comparison of texture components of measured and calculated results

The major texture components deduced from pole figures of the specimen and those of calculated results are listed in Table 6.

From these data, the texture components of surface layers under

Table 6 Major texture components measured and calculated results

\begin{tabular}{lrlll}
\hline $\begin{array}{l}\text { Specimen } \\
\text { number }\end{array}$ & $\begin{array}{l}\text { Depth } \\
\mu \mathrm{m}\end{array}$ & $\begin{array}{l}\text { Texture Components } \\
\text { Measured }\end{array}$ & \multicolumn{2}{l}{ Model Calculated } \\
P1-1 & 100 & $\sim(112)[1 \overline{1} 0]+\sim(112)[\overline{1} 10]$ & 1 -c & $(112)[1 \overline{1} 0]$ \\
& 251 & $\sim(112)[1 \overline{1} 0]+\sim(112)[\overline{1} 10]$ & 1 -c & $(112)[1 \overline{1} 0]$ \\
P2-1 & 109 & $\sim(111)[11 \overline{2}]+\sim(332)[11 \overline{3}]$ & $4-\mathrm{a}$ & $(111)[11 \overline{2}]$ \\
& 178 & $\sim(111)[11 \overline{2}]+\sim(332)[11 \overline{3}]$ & $4-\mathrm{a}$ & $(111)[11 \overline{2}]$ \\
& 301 & $\sim(554)[22 \overline{5}]$ & $4-\mathrm{a}$ & $(111)[11 \overline{2}]$ \\
P3-1 & 96 & $\sim(445)[110]$ & 1 -b & $(111)[1 \overline{1} 0]$ \\
FR-1 & 25 & $\sim(223)[33 \overline{4}]$ or $\sim(332)[11 \overline{3}]$ & 3 & $(556)[33 \overline{5}]$ \\
& 79 & $\sim(223)[1 \overline{1} 0]$ or $\sim(335)[1 \overline{1} 0]$ & $1-\mathrm{b}$ & $(111)[1 \overline{1} 0]$ \\
FR-2 & 25 & $\sim(445)[55 \overline{8}]$ or $\sim(554)[22 \overline{5}]$ & 3 & $(556)[33 \overline{5}]$ \\
& 106 & $\sim(223)[1 \overline{1} 0]+\sim(223)[1 \overline{1} 0]$ & $1-\mathrm{b}$ & $(111)[1 \overline{1} 0]$ \\
Used rail & 0 & $\sim(554)[225]$ & 3 & $(556)[33 \overline{5}]$ \\
Center & 5 & $\sim(554)[22 \overline{5}]$ & 3 & $(111)[21 \overline{3}]$ \\
Field side & 5 & nearly random & & \\
G. C. side & 5 & nearly random & & \\
\hline
\end{tabular}

( $\sim$ : near the orientation) 
nearly pure rolling contact, both cylinders and used rail, agree with those of the axial strain model (Model 3). In the case of rolling contact with small sliding or nearly pure sliding contact, the texture components at inner layer agree with those of rolling model (Model 1-b or 1-c).

Evident preferred orientation was observed at the surface of the specimen both in the disks and in rail where less tangential force was applied. While at the region where severe plastic flow was introduced by a large tangential force, texture was hardly observed.

\section{Acknowledgement}

The present research was financially supported in part by the Nippon Steel Corporation, and the authors are deeply indebted to Mr. K. Sugino for his helpful discussion. They are also grateful to Mr. S. Matsuyama of Railway Technical Research Institute of Japan National Railway for providing us the used rail specimen.

\section{References}

Crook, A. W. (1979). Proc. Instn mech. Engrs, Lond., 171-187.

Dillamore, I. L. and Katoh, H. (1974). Met. Sci. 8, 21.

Dillamore, I. L. and Katoh, H. (1971). Proc. Conf. Quant. Texture Analy., Krakow, $315-344$.

Johnson, K. L. (1963). Proc. Symp. Fatigue in Rolling Contact, Instn mech. Engrs. Lond., 155.

Johnson, K. L. and Jefferis, J. A. (1963). Proc. Symp. Fatigue in Rolling Contact, Instn mech. Engrs. Lond., 54-65.

Merwin, J. E. and Johnson, K. L. ibid (1963). 145-154.

Nagashima, S. Tanaka, N. and Ohtsubo, T. (1984). Advances in X-Ray Analysis, 27, 207-212.

Nagashima, S., Tanaka, N. and Ohtsubo, T. (1986). Proc. Intnl. Conf. Residual Stress, to be published.

Nagashima, S., Tanaka, N., Ohtsubo, T. and Akimoto, K. (1983). J. Soc. Mat. Sci. Japan 32, 1314-1320.

Sugino, K. and Kageyama, H. (1979). Proc. Symposium on "Rolling Contact Between Wheels and Rails", Tech. Res. Lab. JNR., 6.

Welsh, N. C. (1957). Proc. Conf. Lubr. Wear, Instn mech. Engrs, Long., 701 